\title{
KRITIK TERHADAP UNDANG UNDANG NOMOR 25 TAHUN 2007 TENTANG PENANAMAN MODAL (PERSPEKTIF TEORI HUKUM)
}

\author{
Agus Surachman \\ Mahasiswa Program Doktor Pascasarjana Universitas Sebelas Maret, Surakarta. \\ E-mail : surachman.ozzz@yahoo.com
}

Sitasi : Surachman, Agus. Kritik Terhadap Undang Undang Nomor 25 Tahun 2007 Tentang Penenaman Modal (Perspektif Teori Hukum). UNIFIKASI : Jurnal I/mu Hukum, 5(1), 24-32. DOI : https://doi.org/10.25134/unifikasi.v5i1.740 Naskah diterima : 25-11-2017 Naskah direvisi : 22-1-2018 Naskah disetujui : 5-2-2018

\begin{abstract}
Abstrak : Latar belakang untuk mengkritik Undang-Undang Penanaman Modal yaitu Undang-Undang Nomor 25 Tahun 2007 dalam perspektif Teori Hukum. Tujuan Penelitian ini adalah untuk mengatahui dan menganalisis apa pendapat teori hukum terhadap Undang-Undang No. 25 Tahun 2007 tentang Penanaman Modal dan apa yang menjadi tujuan Hukum UndangUndang No. 25 Tahun 2007. Metode penelitian yang digunakan adalah penellitian normative yang meneliti data sekunder dari berbagai bahan hukum primer, sekunder maupun tersier. Hasil penelitian adalah bahwa berdasarkan analisis menggunakan Teori Hans kelsen dengan teorinya The Hirarchies of The norms, teori Jeremy Bentam, dengan teori kemanfataan, terkenal dengan sebutan The greates Happniness of The Greatest number, dan teori Satipto Rahardjo, bahwa hukum adalah untuk manusia bukan manusia untuk hukum bertujuan untuk membahagiakan rakyat maka disimpukan bahwa tidak adanya konsistensi antara pasal-pasal dan tujuan hukum yang terdapat dalam Undang-undang Nomor 25 tahun 2007 tentang penanaman modal, Sehingga dapat menimbulkan ketidakpastian hokum dan tujuan hukum yang ingin dicapai adalah kepastian hukum, kesejahteran, keadilan dan kemakmuran bagi seluruh Rakyat Indonesia. Kesimpulannya bahwa kepada pemerintah dan Dewan Perwakilan Rakyat dalam setiap pembuatan peraturan perundangan yang berkaitan dengan Penanaman modal harus selalu berkiblat kepada Pancasila dan Konstitusi Undang Undang Dasar Negara Republik Iindonesia 1945.
\end{abstract}

Kata kunci : teori hukum, undang-undang no 25 tahun 2007, Pancasila dan UUD 45.

\section{THE CRITICISM OF LAW NUMBER 25 YEAR 2007 ABOUT INVESTMENT (THE PERSPECTIVE THEORY OF LAW)}

\begin{abstract}
Abstrak : The background to criticize the Investment Law is Law Number 25 Year 2007 in the perspective theory of law, the purpose of the research is to know and analyze the opinion of theory and what is the purpose for the Law no. 25 Year 2007 about Investment and what is the purpose of the Law no. 25 Year 2007. The research method uses normative research that examines secondary data from various primary, secondary and tersier materials. The results of the study are based on the analysis using the Hirarchies of the norms, Jeremy Bentam's theory, with theoretical theory, known as the Greates Happniness of the Greatest number, and Satipto Rahardjo's theory, that the law is for human non-which aims to make people happy. it is concluded that the absence of consistency between the articles and the legal objectives contained in Law no. 25 of 2007 about Investment, so that it can lead to legal uncertainty and welfare, justice and prosperity for the whole People Indonesia. The conclusion that to the government and the Parliament (DPR) in every legislative regulation relating to investment should be oriented to Pancasila and the 1945 Constitution of the Republic of Indonesia.
\end{abstract}

Keywords: Theory of Law, Law No. 25 of 2007, Pancasila and the 1945 Constitution of the Republic of Indonesia.

\section{PENDAHULUAN}

Era globalisasi seperti saat ini, penanaman modal terutama penanaman modal asing telah datang bagai air bah yang tidak dapat terbendung, mereka datang dengan segala kebaikan dan keburukannya. Kebaikannya Indonesia telah ikut terlibat dalam pergaulan perdagangan nasional, menumbuhkan keuntungan teknologi dan ekonomi, menyerap tenaga kerja dan lain sebagainya tetapi keburukannya juga ada yaitu datangnya sebuah ideologi kapitalis dalam bentuknya yang baru yaitu neoliberalisme, seperti dikatakan Adi Sulistiyono:

"Sebenarnya kesadaran akan bahaya kapitalisme dalam sosoknya yang sekarang 
UNIFIKASI : Jurnal IImu Hukum, Volume 05 Nomor 01, Januari 2018

ini sudah kian tumbuh, justru dari kalangan pemikir barat sendiri, termasuk para pemikir lembaga-lembaga keuangan international seperti International Monetary Found (IMF), justru kesadaran ini kurang muncul di negara-negara berkembang, sehingga mereka secara "sukarela " menerjunkan diri kedalam ajang permainan yang sedang berkembang."

Menurut Hendrik Budi Untung :

"Untuk menyatukan antara kepentingan investor dengan negara-negara penerima modal harus disadari tidak mudah. Artinya, apabila negara penerima modal terlalu ketat dalam menentukan syaratpenanaman modal investor, mungkin saja para investor tidak akan datang lagi bahkan bagi investor yang sudah adapun bisa jadi akan merelokasi perusahannya.

Disebut demikian, karena di era globalisasi ini, para pemilik modal sangat leluasa dalam menentukan tempat berinvestasi yang tidak terlalui dibatasi ruang geraknya. "2

Indonesia telah membuat UndangUndang No. 25 Tahun 2007 yang telah membuka seluas-luasnya tentang jenis usaha yang dapat diberikan kepada para investor asing. Seperti yang diatur dalam Pasal 12 ayat (1) dan (2), dikatakan: "semua bidang usaha atau jenis usaha terbuka bagi kegiatan penanaman modal, kecuali bidang usaha atau jenis usaha yang dinyatakan tertutup dan terbuka dengan persyaratan. Bidang usaha yang tertutup bagi penanaman modal asing

${ }^{1}$ Adi Sulystiono, 2008, Reformasi Hukum Ekonomi Indonesia. Lembaga Pengembangan Pendidikan (LPP) dan UPT Penerbitan dan Percetakan UNS (UNS Press)Universitas Sebelas Maret Surakarta. Cetakan ke2, Mei, hlm. 14-15

${ }^{2}$ Hendrik Budi Untung, Hukum Investasi, Jakarta:Sinar Grafika, hlm. 5
p-ISSN 2354-5976, e-ISSN 2580-7382

https://journal.uniku.ac.id/index.php/unifikasi

adalah : produksi senjata dan bidang usaha yang secara ekspilsit dinyatakan tertutup berdasarkan undang-undang."

Dari makna pasal tersebut hanya yang dikecualikan tersebut di atas yang tidak bisa jadi bidang usaha penanaman modal, mereka bisa berusaha dibidang pertambangan, perkebunan, air minum, perikanan, pertambakan dan lain sebagainya. Sedangkan dalam Undang-Undang Dasar 1945, Pasal 33 ayat (3), dikatakan "Bumi, air dan kekayaan alam yang terkandung didalamnya dikuasai oleh negara dan dipergunakan sebesarbesarnya untuk kemakmuran rakyat. "Kemudian dipertegas lagi melalui Pasal 2 ayat (1) Undang-Undang No. 5 Tahun 1960 tentang Peraturan Dasar Pokok-Pokok Agraria yaitu: "Bumi, air, dan ruang angkasa, termasuk kekayaan alam yang terkandung didalammnya itu pada tingkatan tertinggi dikuasai oleh negara sebagai organisasi kekuasaan seluruh rakyat."

\section{RUMUSAN MASALAH}

Adapun yang menjadi pokok permasalahan yang akan menjadi fokus perhatian utama yang akan dibahas dalam penulisan ini yaitu Apa pendapat teori hukum terhadap Undang-Undang No. 25 Tahun 2007 tentang Penanaman Modal ? Apa yang menjadi tujuan Hukum Undang-Undang No. 25 Tahun 2007?

\section{METODE PENELITIAN}

Penelitian ini menggunakan penelitian normatif yaitu dengan mengkaji atau menganlisa data sekunder yang terdiri dari bahan-bahan hukum primer, sekunder dan tersier, kemudian dianalisis secara deskriptif, komparatif dan kualitatif kemudian dideduksi untuk menjawab permasalahan yang diteliti. 
UNIFIKASI : Jurnal IImu Hukum,

Volume 05 Nomor 01, Januari 2018

\section{PEMBAHASAN}

Istilah Teori hukum menurut Sudikno Mertokusumo adalah sebagai berikut :

"Istilah yang digunakan untuk apa yang dimaksud dengan teori hukum didalam literatur bermacam-macam. Kata Teori hukum adalahterjemahan 'legal theory', 'Rechtstheory', atau 'rechstheory'. Kata 'legal theory' antara lain digunakan oleh Friedmann (1970), Finch (1979), dan Gijssel (1982). Ada yang menyebutnya 'jurisprudence' (Paton, 1951 ; Posner,1990 ), bahkan ada yang menyebutnya legal philosophy (kelsen, 1917), dan "theory of jastice" ( Rawls, 1972, baca selanjutnya Mc Leod, 1999 : 2 ; Lily Rasjidi, 1990: 1 ). Buku Friedmann berjudul Legal Thery diterjemahkan dalam bahasa Indonesia menjadi "Teori Hukum dan Filsafat Hukum" (1990). " 3

Pengertian teori hukum menurut $W$. Friedmann :

"All sistematic thinking about legal theory is linked at one end with philosophy and, at the other end, with political theory ". 4

Menurut Sudikno :

"Jadi,teori hukum adalah cabang ilmu hukum yang membahas atau menganalisistidak sekedar menjelaskan atau menjawab pertanyaan atau permasalahan secara kritis ilmu hukum maupunhukum positif dengan menggunakan metode interdisipliner.Jadi, tidak hanya menggunakan metode sintesis saja.Dikatakan secara kritis karena pertanyaan-pertanyaan atau permasalahan teori hukum tidak cukup

\footnotetext{
${ }^{3}$ Sudikno Mertokusumo, 2004, Teori Hukum, Cahaya Atma Pustaka edisi revisi, hlm. 1

${ }^{4}$ W. Friedmann, 1949, Legal Theory. London: Stevens\& Sons, limited, hlm. 3
}

p-ISSN 2354-5976, e-ISSN 2580-7382

https://journal.uniku.ac.id/index.php/unifikasi

dijawab secara 'otomatis' oleh hukum positif karena memerlukan argumentasi atau penalaran.Berbeda dengan dogmatik hukum yang jawaban pertanyaan atau permasalahannya sudah ada didalam hukum Positif". ${ }^{5}$

Ada beberapa teori hukum yang dapat kita kemukakan dalam memecahkan persoalan tersebut, seperti yang dikemukakan oleh Hans Kelsen .

"The relation between the norm regulating the creation of another norm and this other norm may be presented as relationship of super-and sub-ordination, which is a spatial figure of speech. The norm determining the creation of another norm is the superior, the norm created according to this regulation, the inferior norm. The legal order, especially the legal order the personification of which is the state, is therefore not a system of norms coordinated to eah other, standing, so to speak, side by side on the same level, but ahierarchy of different levels of norms. The unity of these norms is constituted by the fact that the creation which is determined by a still higher norm, and that this regressus is terminated by ahighest, the basic norm which, beeing the supreme reason of validity of the whole legal order, constitutes its unoity". 6

\section{Artinya :}

"Hubungan antara norma-norma hukum satu dengan yang lainnyadapat dikatakan sebagai hubungansuper dan subordinasi, sebuah kiasan. Norma yang levelnya lebih rendah harus mengacu kepada norma yang diatasnya, norma yang lebih rendah harus

\footnotetext{
${ }^{5}$ Sudikno Mertokusumo, opcit. h/m. 87-88

${ }^{6}$ Hans Kelsen, General Theory of Law and State, Trsaction Publisher New Brunswick (USA) and London ( UK ), hlm.124
} 
UNIFIKASI : Jurnal IImu Hukum, Volume 05 Nomor 01, Januari 2018

sesuai dengan yang lebih tinggi, oleh karena itu system hukum tidak berkoordinasi berdampingan dalam level yang sama tetapi berkoordinasi dalam suatu hirarkiberbagai tingkatan normanorma sebagai sebuah kesatuan hukum yang semuanya bermuara kepada hukum yang tertinggi yaitu norma-norma dasar yang punya alasan untuk memvalidasi seluruh tatanan hokumyang merupakan kesatuan hukum."

Dari teori yang dikembangkan oleh Hans Kelsen, dapat disimpulkan, bahwa seharusnya Undang-Undang tentang Penanaman Modal Asing itu haruslah berada dalam koridor konstitusi UUD 45 dan Pancasila sebagai falsafah bangsa Indonesia. Seperti dikatakan Kelsen, selanjutnya:

"The Hierarchical structure of the legal order of state is roughly as follows: Presupposing the basic norm, the constitution is the highest level within national law. "7

Presupposing the basic norm, kalau di Indonesia adalah Pancasila, selanjutnya Undang-Undang 45 dan peraturan perundangan serta perubahan lainnya. Haruslah bertujuan seperti yang tercantum dalam Konstitusi dan falsafah bernegara yang mempunyai tujuan hukum kita sebagai suatu bangsa.Indonesia adalah negara hukum, diatur dalam Bab I, Pasal 1 ayat 3 UndangUndang Dasar 1945, menyatakan "Negara Indonesia adalah negara hukum."

"Tujuan Negara hukum kita menurut Sri Edi Swsasono, bahwa: Pasal 33 UUD 45 adalah suatu 'raksasa'. Ditetapkannya Pasal 33 UUD 45 merupakan wujud nasionalisme Ekonomi Indonesia, yaitu merupakan tekad kemerdekaan untuk mengganti asas kolonial, yaitu 'asas

${ }^{7}$ Ibid.,hlm. 124
p-ISSN 2354-5976, e-ISSN 2580-7382

https://journal.uniku.ac.id/index.php/unifikasi

perseorangan (individualisme) menjadi asas nasional, yaitu 'kebersamaan dan kekeluargaan' (mutualisme dan brotherhood atau ukuwah). ${ }^{18}$

Sedangkan menurut Satjipto Rahardjo sendiri :

"Pembacaanterhadap Undang-Undang

Dasar kita memunculkan satu nilai moral penting, yaitu menghadirkan dan membangun 'suatu negara dengan komitmen kuat untuk membahagiakan rakyatnya'.Semua hal yang tercantum dalam Pancasila menunjukan komitmen moral tersebut. Sila-sila 'Ketuhanan Yang Maha Esa. Kemanusiaan Yang Adil dan Beradab, Musyawarah dalam mengambil keputusan dan keadilan sosial bagi seluruh rakyat Indonesia'membuat negara memikul amanah untuk menjalankan tugas dengan sekalian moralitas tersebut. Masuknya sila Ketuhanan Yang Maha esa yang meta-rasional, memberikan warna unik dan watak khas serta sekaligus menjadi alasan penting untuk mengatakan, Negara Indonesia menginginkan agar rakyatnya hidup bahagia." 9

Menurut Jeremy Bentham, pembentuk Undang-Undang harus menempatkan kebaikan publik menjadi tujuannya berdasarkan manfaat umum sebagai dasar pemikirannya, yaitu sebagai berikut:

"Kebaikan publik hendaknya menjadi tujuan legislator: manfaat umum menjadi landasan penalarannya. Mengetahui kebaikan sejati masyarakat adalah hal yang membentuk ilmu legislasi; ilmu tersebut tercapai dengan menemukan

\footnotetext{
${ }^{8}$ Satjipto Rahardjo,Negara Hukum Yang Membahagiakan Rakyatnya. Genta Publishing, hlm. 84 ${ }^{9}$ Ibid.,hlm. 85
} 
UNIFIKASI : Jurnal IImu Hukum, Volume 05 Nomor 01, Januari 2018

cara untuk merealisasikan kebaikan tersebut ". 10

Kemudian, dalam pengantar buku $A$ Fragment on Government, Jeremy Bentham. F.C. Montague M.A. mengatakan sebagai berikut :

"if we look in history says Beccaria in his introduction, we shall find that laws which are or ought to be convention between man a state of freedom have been for the most part the work of the possesion of a few or the consequences of fortutions or temporary neccesity: not dictated by a cool examiner of human nature, who knew how to collect. In one point in the action of multitude and had this only end in view, THE GREATEST HAPPINESS OF THE GRETEST NUMBER. This sentence might have been pre fixed to a collected edition of Bentam's writing, and it closing words were adapted by Bentham as the motto of hislifelong labour "."1

Artinya :" jika kita melihat kepada sejarah, kata Beccaria dalam kata pengantarnya, kita akan menemukan hukum kebiasaan antara manusia dan negara dari kebebasan yang telah menjadi bagian dari banyak pekerjaan yang dimiliki, sebagai konsekwensi yang temporer, yang tidak dituliskan sebagai sifat manusia. Siapa yang tahu bagaimana mengumpulkan dalam satu poin didalam tindakan yang begitu banyak yang diakiri dengan suatu kalimat KEBAHAGIAN YANG PALING BESAR ADALAH

${ }^{10}$ Jeremy Bentham, Teori Perundangundangan, diterjemahkan oleh Nurhadi MA, dari The Theory of Legislation,Bandung: Nusa media dan Penerbit Nuansa, hlm. 25

${ }^{11}$ Jeremi Bentham, 2001,A Fargment on Government With an introduction by F.C. Montague. M.A. late fellow of oriel college. The lawbook exchange, Itd. Union, New Jersey, hlm. 27
p-ISSN 2354-5976, e-ISSN 2580-7382

https://journal.uniku.ac.id/index.php/unifikasi

KEBAHAGIAN YANG SEBANYAK-
BANYAKNYA ORANG.Kalimat ini
sebelumnya dipatikan diperoleh dari
kumpuluan-kumpulankarya karya yang
telah ditulis Bentham, dan diakhiri dengan
kalimat yang dipakai sebagai motto oleh
Bentham semasa hidupnya ".

Dari uraian-uraian teori hukum tersebut di atas, mari kita analisa tentang UndangUndang No. 25 Tahun 2007 tentang Penanaman Modal.

Pertama, Tujuan dari Undang-Undang Penanaman Modal. Kita lihat dalam bagianmenimbang:

a. bahwa untuk mewujudkan masyarakat adil dan makmur berdasarkan Pancasila dan Undang-Undang Dasar 1945 perlu dilaksanakan pembangunan ekonomi nasional yang berkelanjutan dengan berlandaskan demokrasi ekonomi untuk mencapai tujuan negara;

b. bahwa sesuai dengan amanat yang tercantum dalam ketetapan Majelis Permusyawaratan Rakyat Republik Indonesia Nomor XVI/MPR1998 tentang Politik Ekonomi dalam rangka demokrasi ekonomi, kebijakan penanaman modal selayaknya selalu mendasari ekonomi kerakyatan yang melibatkan pengembangan bagi usaha mikro, kecil, menengah, dan koperasi;

c. bahwa untuk mempercepat pembangunan ekonomi nasional mewujudkan kedaulatan politik dan ekonomi Indoneia diperlukan peningkatan penanaman modal untuk mengolah potensi ekonomi menjadi kekuatan ekonomi riil dengan menggunakan modal yang berasal, baik dari dalam negeri maupun dari luar negeri;

d. bahwadalam menghadapi perubahan perekonomian global dan keikutsertaan Indonesia dalam berbagai kerjasama 
UNIFIKASI : Jurnal IImu Hukum, Volume 05 Nomor 01, Januari 2018

internasional perlu diciptakan penanaman modal yang kondusif, promotif, memberikan kepastian hukum, keadilan, dan efisien dengan tetap memperhatikan kepentingan ekonomi nasional.

Dari uraian tersebut di atas, ternyata terdapat kesamaan dengan tujuan hukum baik itu yang merujuk kepada UUD 1945 Pasal 33 maupun dengan teori-teori yang dikemukakan oleh para ahli, semuanya bermuara kepada kepentingan ekonomi nasional, kemakmuran, kesejahteraan dan kebahagiaan seluruh Rakyat Indonesia serta kepastian hukum. atauSeperti yang dikatakan oleh Hans Kelsen bahwa norma hukum harus sesuai, bukan saja hanya menciptakan hukum tetapi juga tidak boleh bertentangan dengan norma hukum yang lebih tinggi yaitu Basic Norm.Basic Norm ini merupakan hukum yang paling tinggi tidak ada norma hukum di atasnya.

Tujuan Undang-Undang Penanaman Modal adalah untuk meningkatkan daya saing Indonesia di pasar global yang merosot sejak terjadinya krisis moneter. Secara normatif diharapkan dapat menarik investor ke Indonesia. Disebut demikian, karena dalam Undang-Undang ini tidak dibedakan lagi perlakuan antara penanam modal asing maupun penanam modal dalam negeri. Hal ini sejalan dengan adanya perjanjian multilateral Agreement on Trade Related Investment Measures (TRIMs) yang melarang adanya diskriminasi terhadaqp investor asing dan lokal. ${ }^{12}$

Kedua, tentang pasal-pasal yang ada dalam Undang-Undang Penanaman Modal. Pasal 1 ayat 4, penanaman modal dalam negeri maupun asing bisa dilakukan dalam bentuk

\footnotetext{
${ }^{12}$ Ramlan, Tinjaun Filosofis Aspek Kepastian Hukum Antara Pemerintah Dengan Pemerintah Daerah Dalam Implementasi Undang-Undang Penanaman Modal Di Indonesia, Jurnal IImu Hukum Volume 3 No. 1, hlm. 67
}

p-ISSN 2354-5976, e-ISSN 2580-7382

https://journal.uniku.ac.id/index.php/unifikasi

badan hukum atau perseorangan tetapi dalam Pasal 5 ayat 2 penanaman modal asing wajib dalam bentuk perseroan terbatas berdasarkan hukum Indonesia dan berkedudukan di wilayah Indonesia, kecuali ditentukan lain oleh undang-undang. Hasil analisa, bahwatidak ada konsistensi, antara kedua pasal tersebut.Sehinggamenimbulkan ketidakpastian hukum.

Pasal3ayat 1 huruf d.Asas "perlakuan yang samadan tidak membedakan asal Negara". Dalam Pasal 6 ayat 2 dikatakan, perlakuan yang sama itu tidak berlaku bagi penanam modal dari suatuyang memperoleh hak istimewa berdasarkan perjanjian dengan Indonesia.

Hasil analisa, tidak ada konsistensi antara kedua pasal tersebut, sehingga menimbulkan ketidakpastian hukum.

Pasal 12 ayat (1) dan (2) seperti yang telah diuraikan di atas, bahwa membuka kepada penanaman modal dalam negeri dan asing semua bidang usaha atau jenis usaha apapun kecuali bidang usaha usaha atau jenis usaha yang dinyatakan tertutup dan terbuka untuk umum. Bidang usaha yang tertutup bagi penanam modal asing adalah, produksi senjata, mesiu, alat peledak dan peralatan perang dan bidang usaha usaha yang secara ekspilisit dinyatakan tertutup berdasarkan Undang-Undang.

Dalam prakteknya, investor asing telah melaksanakan usahanya di bidang perkebunan, pertambakan, pertambangan dan pelayaran dan lain sebagainya. Hal ini bertentangan dengan Pasal 33 Undang-Undang Dasar 1945, bahwa bumi, air seta kekayaan alam yang terkandung didalamnya dikuasai oleh negara untuk sebesar-besarnya kemakmuran rakyat $^{13}$.

\footnotetext{
${ }^{13}$ Haris Budiman dan Suwari Akhmaddhian, Implementas Reformasi Birokrasi Bidang Perizinan Pananaman Modal di Kabupaten Kuningan. Jurnal Unifikasi, ISSN 2354
} 
UNIFIKASI : Jurnal IImu Hukum, Volume 05 Nomor 01, Januari 2018

Undang-Undang Penanaman Modal ini lahir pada masih berlangsungnya perdepatan mengenai pentingnnya pengaturan yang lebih tegas terhadap penyelenggaraan investasi di Indonesia. Namun pada kenyataannya, masih timbul pertentangan mengenai pembaharuan Undang-Undang Investasi karena pembaharuan tersebut dianggap akan memeras ekonomi bangsa dengagn cara menguasai serta mengambil sumber-sumber kekayaan alam. Alasan penggantian UUPMA UU No. 1 Tahun 1967 dan Undang-Undang No. 5 Tahun 1968 tentang Penenaman Modal Dalam Negeri (UUPMDN) dengan UUPM, dikaitkan dengan Indonesia sebagai anggota WTO Agreement dengan Undang-Undang Nomor 7 Tahun 1994 tentang Pengesahan WTO. ${ }^{14}$

Pasal 10 ayat (1) perusahaan penanaman modal dalam memenuhi kebutuhan tenaga kerja harus mengutamakan tenaga kerja warga negara Indonesia, (2) perusahaan penanaman modal berhak menggunakan tenaga ahli warga negara asing untuk jabatan dan keahlian tertentu sesuai dengan ketentuan peraturan perundang-undangan, (3) perusahaan penanaman wajib meningkatkan kompetensi tenaga kerja warga negara Indonesia melalui pelatihan kerja sesuai dengan ketentuan peraturan perundangundangan. Dalam Pasal ini tidak ditentukan dengan jelas, apa sanksinya bagi perusahaan yang tidak melaksanakan ketentuan Pasal 10 ayat 3 tersebut.

Pasal 22 ayat (1), (2) dan (4) yang memuat tentang fasilitas hak-hak atas tanah telah dibatalkan oleh Mahkamah Konstitusi,

5976 Vol. 1 No. 1 Oktober 2013. Hlm. 1-19. https://doi.org/10.25134/unifikasi.v1i1.28

14 Acep Rohendi, Prinsip Liberalisasi Perdagangan WTO dalam Pembaharuan Hukum Investasi di Indonesia (Undang-Undang Nomor 25 Tahun 2007), Padjajaran Jurnal IImu Hukum, Volume 1- No. 2- Tahun 2014.hlm. 388
p-ISSN 2354-5976, e-ISSN 2580-7382

https://journal.uniku.ac.id/index.php/unifikasi

sepanjang menyangkut kata-kata "dimuka sekaligus".

"Pasal 22 ayat (1), (2) dan ( 4 ) telah dibatalkan oleh Mahkamah Konstitusi dengan Putusan Mahkamah Konstitusi Republik Indonesia, perkara No 2122/PPU-V/2007, Perihal Pengujian Undang-Indang RI. No.25 tahun 2007 tentang PM terhadap UUD 45". ${ }^{15}$

Bahkan pasal ini juga bertentangan dengan Undang-Undang Pokok Agraria, yaitu mengenai jangka waktu pemberian hak atas tanah dan cara pemberiannya. Dalam UUPMA jangka waktunya lebih lamadan cara pemberiannya kalau UUPA secara bertahap dalam UUPMAdimuka sekaligus.

Pasal 22 Undang-Undang No. 25 Tahun 2007pasca putusan MK menjadi berbunyi :

1) kemudahan pelayanan dan/atau perizinan hak atas tanah sebagaimana dimaksd dalam Pasal 21 huruf a dapat diberikan dan diperpanjang dan dapat diperbaharui kembali atas permohonan penanam modal;

2) hak atas tanah sebagaimana dimaksud pada ayat (1) dapat diberikan dan diperpanjang untuk kegiatan penanaman modal, dengan persyaratan antara lain :

a) penanaman modal yang dilakukan daqlam jangka panjang dan terkait dengan perubaha struktur perekonomian Indonesia yang lebih berdaya saing:

b) penanaman mdal dengan tingkat resiko penanaman modal yang memerlukan pengembalian modal dalam jangka panjang sesuai dengan jenis kegiatan penanaman modal yang dilakukan;

\footnotetext{
${ }^{15}$ Putusan Mahkamah Konstitusi Republik Indonesia, perkara No 21-22/PPU-V/2007 hlm.80
} 
c) penanaman yang tidak memerlukan area yang luas;

d) penanaman modal dengan menggunakan hak atas tanah negara;

e) penanaman modal yang tidak mengganggu rasa keadilan masyarakat dan tidak merugikan kepentingan umum.

3) Hak atas tanah dapat diperbaharui setelah dilakukan evaluasi bahwa tanahnya masih digunakan dan diusahakan dengan baik sesuai dengan jeadaan, sifat dan tujuan pmberian hak.

4) Pemberian dan perpanjangan hak atas tanah yang diberikan dan yang dapatdiperbaharui sebagaimana dimaksud pada ayat (1) dan ayat (2) dapat dihentikan atau dibatalkan oleh pemerintah jika perusahaan penanam modal menelantarkan tanah, merugikan kepentingan umum, menggunakan atau memanfaatkan tanah tidak sesuai dengan maksud dan tujuan pemberian hak atas tanahnya, serta melanggar ketentuan peraturan perundang-undangan di bidang pertanahan. ${ }^{16}$

Sebagai akibat dinyatakan inskonstitusioanalnya sebagian ketentuan pasal 22 Undang-Undang Nomor 25 tahun 2007 tentang Penanaman Modal tersebut, maka terhadap pemberian kemudahan dan/atau pelayanan kepada Perusahaan Penanaman Modal untuk memperoleh Hak Atas Tanah, sepanjang berkaitan langsung dengan Penanaman Modal, ketentuan yang berlaku adalah keentuan yang terdapat dalam peraturan perundang-undangan lainnya ${ }^{17}$.

16 Efrimol, Kebijakan Pemerintah Tentang Pengaturan Mengenai Pertanahan Dalam Penanaman Modal Dan Invesatasi Di Indonesias, Jurnal Ilmu Hukum, (SI), V.4.n, Juli 2011, HIm. 50

17 Zulfi Diane Zani, Pengaturan Kepemilikan Atas Tanah Sebagai Pendukung Kegiatan Investasi di

\section{SIMPULAN}

Dari uraian tersebut dapat disimpulkan sebagai berikut :

1. Tidak adanya konsistensi antara pasalpasal dan tujuan hukum yang terdapat dalam Undang-undang No. 25 tahun 2007 tentang penanaman modal, Sehingga dapat menimbulkan ketidakpastian hukum;

2. Tujuan hukum yangingin dicapai adalah kepastian hukum, kesejahteran, keadilan dan kemakmuran bagi seluruh Rakyat Indonesia.

\section{SARAN}

1. Melakukan perubahan terhadap pasalpasal yang saling bertentangan dan menyerasikannya dengan tujuan pembuatan Undang-Undang No. 25 Tahun 2007, serta menempatkan kembali dalam bingkai Pancasila dan UUD 1945;

2. Ikut aktif mengarahkan lajunya globalisasi dan kapitalis yang tidak berwajah serakah dan menghalalkan segala cara. Tapi membentuknya menjadi globalisasi investasi yang ramah, lingkungan, suasana usaha yang beretika serta bermanfaat tidak saja bagi investor tetapi juga masyarakat Indonesia, agar tercipta keadilan, kesejahteraan, kebahagian, kedamaian dan kepastian.

\section{DAFTAR PUSTAKA}

Akhmaddhian, Suwari. Penegakan Hukum Lingkungan dan Pengaruhnya Terhadap Pertumbuhan Ekonomi di Indonesia (Studi Kebakaran Hutan Tahun 2015) Jurnal Unifikasi, ISSN 2354-5976 Vol. 03 Nomor 01 Januari

Indonesia ( Perkembangan Hukum Bisnis Dalam era Golabisasi), cetakan pertama, Desember 2017, Corleone Books ( corbooks), Publishing House Of Literia Media, Sariwangi Regency- blok cemara no. 21 Bandung 40559 hlm 53 . 
UNIFIKASI : Jurnal IImu Hukum, Volume 05 Nomor 01, Januari 2018

2016.

DOI:

https://doi.org/10.25134/unifikasi.v3 i1.404

Bentham, Jeremy. 2001. A Fargment on Government. With an introduction by F.C. Montague. M.A. late fellow of oriel college. The lawbook exchange, Itd. Union, New Jersey.

Bentham, Jeremy. 2006. Teori Perundangundangan. The Theory of legislatioan, diterjemahkan oleh Nurhadi MS, editor Derta Sri Wuladari, Pembaca Pruf, Matori A. Elwa. Bandung : Penerbit Nusa Media \& Penerbit Nuansa.

Budiman, Haris dan Suwari Akhmaddhian, Implementasi Reformasi Birokrasi Bidang Perizinan Pananaman Modal di Kabupaten Kuningan. Jurnal Unifikasi, ISSN 2354-5976 Vol. 1 No. 1 Oktober 2013. Hlm. 1-19. https://doi.org/10.25134/unifikasi.v1 i1.28.

Efrimol. 2011, Kebijakan Pemerintah Tentang Pengaturan Mengenai Pertanahan Dalam Penanaman Modal Dan Invesatasi Di Indonesias, Jurnal Ilmu Hukum, (SI), V.4.n.2, Juli 2011.

Friedmann, W. 1949 Legal Theory, London, stevens\& sons, limited.

Kelsen. Hans. 1949. General Theory of Law and State, Harvard University Press.

Mertokusumo, Sudikno. 2004. Teori Hukum, Yogyakarta: Cahaya Atma Pustaka.

Raharjo, Satjipto. 2009. Negara Hukum yang Membahagiakan Rakyatnya, Yogyakarta : Genta Publishing

Ramlan, Tinjaun Filosofis Aspek Kepastian Hukum Antara Pemerintah Dengan Pemerintah Daerah Dalam Implementasi Undang-Undang Penanaman Modal Di Indonesia, Jurnal IImu Hukum Volume 3 No. 1,
p-ISSN 2354-5976, e-ISSN 2580-7382

https://journal.uniku.ac.id/index.php/unifikasi

Rohendi, Acep. 2014,Prinsip Liberalisasi Perdagangan WTO dalam Pembaharuan Hukum Investasi di Indonesia (Undang-Undang Nomor 25 Tahun 2007), Padjajaran Jurnal IImu Hukum, Volume 1- No. 2. 2014.

Sulistyono, Adi. 2008, Reformasi Hukum

Ekonomi Indonesia, Universitas Sebelas Maret, Surakarta.

Untung, Hendrik Budi . 2010. Hukum Investasi, Jakarta : Sinar Grafika.

Zaini, Zulfi Dane, 2017 Pengaturan Kepemilikan Hak Atas Tanah Sebagai Pendukung Kegiatan Invesasi di Indonesia (Perkembangan Hukum Bisnis Dalam Era Globalisasi). Corleone Books (Corbooks) Publishing House Of Literia Media, Bandung.

Undang Undang Dasar Negara Republik Indonesia Tahun 1945

Undang-Undang No. 25 Tahun 2007 Tentang Penanaman Modal

Putusan Mahkamah Konstitusi Republik Indonesia, perkara no 21-22/PPUV/2007 Perihal Pengujian UndangUndang RI. No.25 tahun 2007 tentang Penanaman Modal terhadap Undang-Undang Dasar 1945 